\title{
ABORDAGEM DA SEPARAÇÃO DE MISTURAS NO ENSINO FUNDAMENTAL SOB O ENFOQUE CTSA VISANDO A CONTEXTUALIZAÇÃO NO ENSINO DE CIÊNCIAS
}

\section{APPROACH TO THE SEPARATION OF MIXTURES IN FUNDAMENTAL EDUCATION UNDER THE CTSA APPROACH AIMING CONTEXTUALIZATION IN SCIENCE TEACHING}

\author{
Dr. Carlos Alberto Vasconcelos \\ Universidade Federal de Sergipe - geopedagogia@yahoo.com.br \\ Bruno dos Santos Andrade \\ Universidade Federal de Sergipe - beast_boybruno@hotmail.com
}

\begin{abstract}
Resumo
Discussões de temas relacionados à Ciência e à Tecnologia têm ocupado uma posição de destaque em meio à conjuntura atual da sociedade. No cenário educacional brasileiro, especificamente no campo do ensino de Ciências, isso tem repercutido em propostas e reformas. Diante do exposto, foi realizada uma análise experiencial com discussão acerca de uma sequência didática referente ao conteúdo Separação de Misturas sob o enfoque CTSA, em uma escola de Ensino Fundamental. Desta análise, constatou-se que os estudantes foram capazes de inter-relacionar o conteúdo com aspectos científicos, tecnológicos, sociais e ambientais; que a incorporação de práticas pedagógicas por parte dos educadores estimula a aprendizagem por meio da utilização do conhecimento científico no exercício da cidadania e promove o desenvolvimento intelectual do estudante com criticidade.
\end{abstract}

Palavras-chave: Ensino de Ciências, Enfoque CTSA. Separação de Misturas. Ensino Fundamental.

\section{Summary}

Discussions of topics related to Science and Technology have occupied a prominent position in the current society. In the Brazilian educational scenario, specifically in the field of science teaching, this has had repercussions on proposals and reforms. In view of the above, an experiential analysis was conducted with a discussion about a didactic sequence regarding the content of Mixtures under the CTSA approach, in a Elementary School. From this analysis, it was verified that the students were able to interrelate the content with scientific, technological, social and environmental aspects; That the incorporation of pedagogical practices by educators stimulates learning through the use of scientific knowledge in the exercise of citizenship and promotes the intellectual development of the student with criticality.

Keywords: Science Teaching. CTSA Approach. Separation of Blends. Elementary School. 


\section{Introdução}

Atualmente, vivemos em um contexto em que a Ciência e a Tecnologia têm exercido um papel de destaque sobre as atitudes e decisões individuais e/ou coletivas dos cidadãos. Embates relacionados a essa temática têm sido amplamente divulgadas e questionadas discutindo sua função na sociedade, consequências e desenvolvimento para o ambiente.

No cenário educacional brasileiro o papel exercido pela Ciência e pela Tecnologia tem repercutido em movimentos que apresentam propostas de reforma a fim de que a educação abranja e acompanhe as transformações oriundas do desenvolvimento dessas áreas. O enfoque CTSA (Ciência, Tecnologia, Sociedade e Ambiente), por exemplo, está voltado para o ensino das ciências, visando ao pleno desenvolvimento do cidadão comprometido com as questões sociais e ambientais, e permite, juntamente com a utilização de instrumentos cognitivos, compreender as inter-relações entre as dimensões abarcadas, favorecendo a participação nas discussões acerca da Ciência e Tecnologia, bem como a compreensão de seus impactos na sociedade.

A partir deste cenário, far-se-á para maior entendimento uma retrospectiva sucinta do movimento CTS. A terminologia CTS é utilizada pelo PCN (Parâmetros Curriculares Nacionais) de Ciências a partir de 1997, e de acordo com Tomazello (2009, p. 1), "a sigla tradicional, relacionada ao movimento Ciência, Tecnologia e Sociedade, é CTS". A partir das décadas de 1970 e 1980, as questões ambientais foram incorporadas ao movimento, "[...] razão pela qual muitos também adotam a sigla CTSA (Ciência-TecnologiaSociedade-Ambiente) que acrescenta o ambiente como mais um foco de análise nas inter-relações da tríade" (SANTOS, 2008, p. 118). Atualmente, um número expressivo de pesquisadores utiliza essa denominação para salientar o aspecto ambiental, conforme cita Marcondes (2009, p. 34), "a utilização do termo CTSA em detrimento do CTS se refere ao fato de os autores considerarem a importância das questões ambientais no ensino e suas relações ciência/tecnologia/sociedade". Neste trabalho optou-se por fazer menção à sigla CTSA, tendo em vista o agravamento dos problemas ambientais e mediante suas implicações na sociedade.

Com esta compreensão emerge a proposta de promover um ensino que permita ao estudante utilizar os conhecimentos científicos para entender e agir sobre o meio em que vive, configurando-se em um desafio para o ensino de Ciências. Nesta perspectiva constituem questões relevantes: como ensinar Ciências com esse entendimento cogente? Quais metodologias utilizar para a construção do conhecimento? Espera-se ao longo deste escrito apontar respostas e formas inovadoras de se trabalhar com esta proposta.

No Brasil, a tendência de incorporar ao ensino a relação entre Ciência, Tecnologia, Sociedade e Ambiente surge durante a década de 1970, juntamente com outros países, e ganha força com a publicação de estudos no início dos anos 1990 pelos cursos de pósgraduação na área de ensino de Ciências. O surgimento de novas propostas para o currículo do ensino de Ciências pautado no enfoque CTSA também emerge das discussões que se intensificaram, principalmente em países de primeiro mundo, como a Inglaterra, EUA e Canadá a partir de 1970, decorrente do agravamento da problemática 
ambiental. Na educação brasileira, esse novo enfoque no currículo demanda a reestruturação do ensino de Ciências. Conforme destacam os PCN de Ciências:

É necessária a construção de uma estrutura geral da área que favoreça a aprendizagem significativa do conhecimento historicamente acumulado e a formação de uma concepção de ciência, suas relações com a tecnologia e com a sociedade (BRASIL, 1997, p. 4).

Desta feita, no campo educacional, o enfoque CTSA tem sido divulgado amplamente através de pesquisas envolvendo o processo de ensino-aprendizagem autores como Auler, 2003; Moraes e Araújo, 2012; Santos, 2005; Sasseron e Carvalho, 2008, discutem a questão.

Dentre estes, Silva (2010, p. 31) acrescenta:

[...] os pressupostos do movimento CTS têm se ampliado em toda a sociedade, ganhando mais adeptos, principalmente na área educacional. De um modo geral, compreende uma área em que os estudos se concentram na preocupação em abordar a C\&T, buscando retratar suas relações com o âmbito social.

Apresentados alguns breves aspectos a respeito da relevância desta temática, é preciso refletir acerca da educação em Ciências que esteja voltada para os interesses do país. É seguindo essa linha de pensamento que a proposta CTSA fortalece a ideia de conceber novos cidadãos a partir de um ensino mais significativo e neste sentido desenvolvemos uma experiência no Ensino Fundamental em uma escola localizada no interior de Sergipe, visando ampliar os objetivos formativos.

Segundo concepções de Linsingen (2007, p. 32) sobre a proposta CTSA:

Educar numa perspectiva CTSA é, fundamentalmente, possibilitar uma formação para maior inserção social das pessoas no sentido de se tornarem aptas a participar dos processos de tomadas de decisões conscientes e negociadas em assuntos que envolvam ciência e tecnologia.

Por certo que promover uma educação científica pautando-se nas inter-relações CTSA rompe com a visão tradicionalista do ensino. Esta visão é caracterizada pela mera transmissão de conteúdos sem a preocupação com a formação crítica dos estudantes, o que compromete o desenvolvimento de algumas competências e habilidades.

Assim, esse texto relata uma experiência didática que teve como foco principal desenvolver e analisar formas diferenciadas de trabalhar em sala de aula conteúdos específicos, no caso misturas com mercúrio na extração do ouro dentro do enfoque CTSA, visando inovar a prática docente e aprimorar o processo de ensino e de aprendizagem, enveredando para a formulação de um contexto educacional que favoreça a construção do conhecimento em uma perspectiva de cidadania/cotidianidade. Para seu desenvolvimento, optou-se por uma abordagem qualitativa com a elaboração de uma sequencia didática em uma escola de Ensino Fundamental.

A princípio, a proposta foi apresentada pelo professor e discutida com os alunos. Feito isso, constatou-se que os estudantes compreenderam a proposta de inter-relacionar 
o conteúdo com aspectos científicos, tecnológicos, sociais e ambientais. Entende-se que a incorporação de práticas pedagógicas inovadoras por parte dos educadores deve estimular a aprendizagem por meio da utilização do conhecimento científico no exercício da cidadania e promover o desenvolvimento intelectual do estudante com criticidade, além de aperfeiçoar a metodologia no ensino de Ciências.

\section{Ensino de Ciências: tendências históricas}

O ensino de ciências no decorrer de sua história até a atualidade vem sofrendo influências de diversos movimentos e tendências que geram reflexos nas salas de aula. Conjunturas mundiais, como a Guerra Fria, Revolução Tecnológica e Globalização podese dizer, foram o tripé principal para as chamadas reformas no ensino de Ciências (KRASILCHIK, 2000).

A disciplina Ciências Naturais nem sempre foi um dos componentes curriculares das séries iniciais do Ensino Fundamental. De acordo com o PCN de Ciências, até a promulgação da Lei de Diretrizes e Bases da Educação Nacional - LDBN no. 4.024/61 ministravam-se aulas de Ciências Naturais apenas nas duas últimas séries do curso ginasial. Essa lei estendeu a obrigatoriedade do ensino dessa disciplina a todas as séries ginasiais: "Somente a partir de 1971, com a Lei $\mathrm{n}^{\circ}$. 5.692, o componente curricular Ciências Naturais passou a ter caráter obrigatório nas oito séries do primeiro grau" (BRASIL, 1997, p. 19).

O panorama educacional até então, era dominado pelo ensino tradicionalista, no qual os professores transmitiam o conhecimento e os estudantes deveriam reproduzi-lo da mesma forma que receberam. A eles cabia a assimilação das informações. Em 1950, o mundo vivia uma situação que demandava uma reforma urgente no ensino, e em especial no de Ciências. Conforme cita Krasilchik (1997, p. 12), "a industrialização, o desenvolvimento tecnológico e científico que vinham ocorrendo não puderam deixar de provocar choques no currículo escolar".

No Brasil, as primeiras transformações começaram a ocorrer também por propostas dos movimentos da Escola Nova, dentre elas as alterações nos currículos que:

[...] incluíam a substituição dos métodos expositivos pelos chamados métodos ativos, dentre os quais tinha preponderância o laboratório. As aulas práticas deveriam propiciar atividades que motivassem e auxiliassem os alunos na compreensão de conceitos. 'Aprender fazendo' resumia a grande meta das aulas práticas (KRASILCHIK, 1997, p. 18).

A década de 1960 foi marcada pela modernização e desenvolvimento do país pressionado pelo regime militar. Evidencia-se também nesse período a vivência do método científico pelos estudantes, o que revela o objetivo do ensino para essa década: a formação de cientistas. Isso fica bem claro quando encontramos no PCN de Ciências que o objetivo do ensino dessa disciplina passou a ser o de "dar condições para o aluno identificar problemas a partir de observações sobre um fato, levantar hipóteses, testá-las, 
refutá-las e abandoná-las quando fosse o caso, trabalhando de forma a tirar conclusões sozinho" (BRASIL, 1997, p. 20).

Como consequência do desenvolvimento industrial acelerado após a Segunda Guerra Mundial, em meados dos anos 1970, o mundo sofria com os sintomas da crise energética. Os problemas relativos ao meio ambiente e à saúde começaram a ter presença quase obrigatória em todos os currículos de Ciências Naturais (BRASIL, 1997). Em nosso país, o período é caracterizado pela promulgação da Lei no . 5.692/71. A escola secundária deve servir agora não mais à formação do futuro cientista ou profissional liberal, mas principalmente ao trabalhador, membro essencial para responder às demandas do desenvolvimento (KRASILCHIK, 1997).

$\mathrm{Na}$ década seguinte, como afirmam os PCN: "nos anos 80 a análise do processo educacional passou a ter como tônica o processo de construção do conhecimento científico pelo próprio aluno" (BRASIL, 1997, p. 9). Desta fase tem-se o construtivismo como proposta metodológica voltada ao ensino e aprendizagem na qual leva-se em consideração que o aprendizado se dá pela interação professor/estudantes/conhecimento, ao se estabelecer um diálogo entre as ideias prévias dos estudantes e a visão científica atual, com a mediação do professor, entendendo que o estudante reelabora sua percepção anterior de mundo ao entrar em contato com a visão trazida pelo conhecimento científico (BRASIL, 1997).

Dos anos 1990, principalmente, até os dias atuais, vive-se uma busca constante de enfretamento dos desafios de uma sociedade, que se transforma e exige continuamente dos cidadãos a tomada de decisões, em meio a uma complexidade social crescente, inclusive em defesa do meio ambiente, e tenta acompanhar o avanço tecnológico, pois a Ciência e a Tecnologia vêm desempenhando um papel fundamental na sociedade contemporânea globalizada.

De certo, é notório que sempre se têm discutido possibilidades para o ensino de Ciências ou tentativas de revolucionar o modo de ensinar e fazer com que os estudantes aprendam com vistas a poderem utilizar o conhecimento construído para exercer sua cidadania. Todavia, há ainda necessidade de ampliar as mudanças para que os educandos envolvam-se mais na busca do saber, consolidando novas propostas educacionais.

Então, não é de hoje que se tenta melhorar o ensino de Ciências no Brasil. Vários pioneiros contribuíram para isso, com seus pensamentos e orientações, conforme destaca Krasilchik (1997):

Rever a história das propostas de mudanças referentes ao ensino das ciências nos últimos quarenta anos serve a um duplo propósito: analisar algumas das transformações do currículo escolar e relacionar essas mudanças ao papel atribuído às disciplinas científicas na formação dos alunos (KRASILCHIK, 1997, p. 5, grifo nosso).

No século XXI o ensino de Ciências passa cada vez mais por inovações: nas escolas, nas universidades, nas políticas curriculares. São realizados encontros, simpósios, reuniões, constituídos programas de pós-graduações em ensino de Ciências; 
há uma maior valorização dos diferentes saberes e das concepções dos professores; preocupação com a divulgação das Ciências na mídia, centros culturais, universidades, e surgem as novas "estações de ciências" (LOPES, 2004). Ou seja, esse novo ensino de Ciências objetiva a formação de jovens alfabetizados do ponto de vista científico, além de que os mesmos utilizem o conhecimento cientifico na atuação pessoal na sociedade, permitindo o acompanhamento do avanço da Ciência e da Tecnologia e a influência que essas áreas operam na vida, inclusive no mercado de trabalho.

\section{Procedimentos metodológicos}

Pelo exposto até aqui, pela relevância do tema e pela busca por uma educação que promova a cidadania dos estudantes, estimulando a capacidade de discutir, criticar e tomar decisões frente à realidade vivenciada por eles, percebe-se que o ensino de Ciências pautado nas inter-relações CTSA pode contribuir como alternativa para o panorama social hodierno. Os docentes têm encontrado desafios diante da nova realidade do Ensino Fundamental, especificamente nesta área do saber, embasados nas propostas que podem ser encontradas nos documentos oficiais. Nesse sentido, de acordo com os PCN, e em especial os de Ciências, um dos objetivos para o Ensino Fundamental é que "o aluno desenvolva competências que the permitam compreender o mundo e atuar como indivíduo e como cidadão, utilizando conhecimentos de natureza científica e tecnológica" (BRASIL, 1997, p. 39).

Dessa feita, a proposta deste texto é suscitar discussões e reflexões sobre uma prática desenvolvida no Ensino Fundamental na disciplina de Ciências, descrevendo interrelações CTSA, a partir do conteúdo Separação de Misturas em uma turma de 30 alunos do $9^{\circ}$ ano de uma escola particular de Ensino Fundamental no município de Carmopólis, em Sergipe. Ressalta-se que este município é o principal produtor de petróleo do estado de Sergipe.

Esta investigação emergiu do interesse em analisar e exemplificar alternativas que possibilitem aos docentes de Ciências atuarem em sala de aula em consonância com os acontecimentos do cenário contemporâneo, além de contemplar as orientações para essa disciplina presentes nos documentos oficiais para o Ensino Fundamental, bem como explicitar entendimentos de alunos a partir da prática desenvolvida propiciando uma aprendizagem mais significativa.

Desta feita, optou-se na metodologia por uma abordagem qualitativa que "[...] se desenvolve numa situação natural, e rica em dados descritivos, tem um plano aberto e flexível, focaliza a realidade de forma complexa e contextualizada" (LÜDKE e ANDRÉ, 1986, p.18). Para tal, foi organizada uma sequência de quatro aulas baseadas no modelo proposto por Aikenhead (1994, apud SANTOS e SCHNETZLER, 2003) sobre o conteúdo Separação de Misturas, como ilustra o Quadro 1.

Para a coleta de dados fez-se um levantamento bibliográfico sobre a temática, analisou-se exemplos de livros didáticos de ciências do 9ำ ano, além do prescrito para 
esta turma e, solicitou-se que cada estudante redigisse um texto de aproximadamente 20 linhas em que respondesse às seguintes perguntas:

- Onde se localizava o garimpo e em que época essa atividade ocorreu?

- No Brasil, qualquer pessoa pode explorar uma riqueza mineral? Comente;

- Quais são, geralmente, as condições sociais e de trabalho de um garimpeiro? Tome Serra Pelada como exemplo;

- O que é bamburro'? A ilusão do bamburro faz com que os garimpeiros se sujeitem a explorações;

- Qual o papel do mercúrio na extração de ouro e o que sua liberação afeta no ambiente?

\begin{tabular}{|l|l|}
\hline 1. Questão social introduzida. & $\begin{array}{l}\text { 1. A turma assiste ao documentário da TV } \\
\text { Cultura: "Serra Pelada: esperança não é } \\
\text { sonho"” e posteriormente há uma discussão } \\
\text { acerca deste. }\end{array}$ \\
\hline $\begin{array}{l}\text { 2. Uma tecnologia relacionada } \\
\text { ao tema social é analisada. }\end{array}$ & $\begin{array}{l}\text { 2. Mercúrio na extração do ouro } \\
\text { (apresentação inicial e análise). }\end{array}$ \\
\hline $\begin{array}{l}\text { 3. O conteúdo científico é } \\
\text { trabalhado. }\end{array}$ & $\begin{array}{l}\text { 3. Separação de Misturas (Métodos de } \\
\text { separação). }\end{array}$ \\
\hline $\begin{array}{l}\text { 4unção dos conteúdos. } \\
\text { f. Mercúrio na extração do ouro (retomada } \\
\text { da análise com base nos conceitos } \\
\text { estudados). }\end{array}$ \\
\hline $\begin{array}{l}\text { Retomada da questão social. (Re)discussão do vídeo a partir dos } \\
\text { conteúdos estudados e das implicações } \\
\text { sociais, econômicas, políticas e ambientais. }\end{array}$ \\
\hline
\end{tabular}

Quadro 1. Sequência de aulas baseada na concepção CTSA

A atividade de elaboração do texto foi realizada individualmente após a exibição do documentário sobre Serra Pelada e posterior discussão, suscitando reflexões. Além disso, solicitou-se que para ilustrar o texto, cada aluno criasse uma teia alimentar explicando como o mercúrio presente na água chega ao organismo humano.

No desenvolvimento da sequência de aulas, o conteúdo foi trabalhado concomitantemente em sala de aula e no laboratório da escola. Durante as aulas no laboratório foi utilizado como material de apoio o escrito de Sartori et al. ${ }^{3}$ (2009), que propõe a construção de um destilador com materiais simples.

\footnotetext{
${ }^{1}$ Mato fechado, geralmente onde se procurava metais preciosos.

2 O vídeo do documentário está disponível em: <http:// www.videos.ac.gov.br/?p=1825>.

${ }^{3}$ Artigo utilizado para confecção do destilador, disponível em <http:// www.qnesc.com.br>.
} 


\section{Discutindo os resultados}

De tempos em tempos emergem discussões e movimentos que têm o intuito de melhor conceber o ensino embasado em questões sociais contemporâneas. Nesse sentido, Pozo e Crespo (2009, p. 23) afirmam que "[...] as formas de aprender e ensinar fazem parte da cultura que todos devemos aprender e sofrem modificações com a própria evolução da educação e dos conhecimentos que devem ser ensinados".

Durante o desenvolvimento da sequência didática, foram feitas algumas notas (escritas) para enriquecer os dados coletados. As notas levavam em consideração o comportamento da turma, a participação, as opiniões e questionamentos levantados pelos estudantes durante cada etapa da sequência. Os dados colhidos serão apresentados de maneira descritiva, dando ênfase àqueles que têm maior relevância para este trabalho.

Na primeira preleção da sequência em sala de aula foi explicado à turma como o conteúdo "Separação de Misturas" seria trabalhado. Por se tratar de uma proposta diferente de trabalho, a turma ficou entusiasmada e concordou em colaborar. Consequentemente e no dia seguinte foi exibido o documentário a partir da projeção em tela por datashow e notebook. Após exibição, que levou em torno de $1 \mathrm{~h} 30 \mathrm{~min}$, inicia-se a discussão do documentário "Serra Pelada: esperança não é sonho" que propiciou aos estudantes a oportunidade de expressarem suas opiniões acerca da temática abordada. Ao serem instigados sobre os pontos relativos a aspectos sociais, econômicos, políticos e ambientais, as falas de grande parte da turma mostravam-se consistentes e coesas, apesar de ser o primeiro contato com a proposta.

A seguir algumas falas retratam a contextualização exposta, bem como a construção do conhecimento em torno da temática abordada: "Antes o lugar do garimpo não tinha movimento, a natureza era intocada. Na época com esta multidão de pessoas em busca de enriquecimento devasta-se o ambiente" (Paládio, 14 anos).

O garimpo para muitos propicia uma boa qualidade de vida, apesar das precárias condições de vida e trabalho (Platina, 13 anos).

Para a maioria, no período, a vida lá fora era ainda mais dura, e sem qualquer perspectiva de melhora. Lá todos tinham trabalho e comida, com direito a sonhar (Pepita, 15 anos).

Outros depoimentos se seguiram demonstrando que o documentário favoreceu o estímulo da capacidade de criticar alguns pontos do vídeo. Destacou-se uma das falas dos estudantes no momento da discussão quando um deles disse que "no garimpo não havia mulheres trabalhando junto com os homens" (Gema, 14 anos). Nesse instante ficou clara a questão de gênero, pois parte da turma afirmava que, por se tratar de um trabalho pesado, as mulheres não teriam condições físicas de exercê-lo.

Ficou nítido a preocupação com a preservação do meio ambiente, com a capacidade do homem de alterar o ambiente em seu próprio favor sem a preocupação com as consequências dessas modificações em longo prazo. Este fato leva-nos a refletir acerca do que propõem os PCN quando afirmam que o ensino de Ciências deve ser concebido com o objetivo de desenvolver competências e habilidades nos estudantes, 
dentre as quais destacamos a de "compreender a natureza como um todo dinâmico, sendo o ser humano parte integrante e agente de transformações no mundo em que vive" (BRASIL, 1997, p. 39).

O documentário destaca as condições sociais, econômicas, políticas, entre outras, da comunidade que se formou na região e mantém-se com o surgimento do garimpo de Serra Pelada. A realidade explorada no vídeo despertou o interesse de entender o contexto, além da extração do ouro. Também salientaram questões de saneamento básico, educação, emprego e problemas socioambientais envolvendo a população daquela área e até mesmo comparando com nossa realidade.

Ao analisar os textos redigidos, constatou-se maior propriedade dos alunos nas colocações acerca da temática. Isso se deve ao fato de esta ter sido discutida em um primeiro momento. É importante salientar que os estudantes poderiam utilizar as redes sociais virtuais, livros, enciclopédias, revistas e outros recursos para subsidiar a escrita do texto. Apesar da gama de fontes, os escritos traziam consigo uma identidade, pois poucos deles eram trechos copiados da internet. Além disso, a teia alimentar montada por cada aluno expressou a forma como os educandos organizaram as ideias e utilizaram o conhecimento para construir cada modelo.

A proposta de montar uma teia alimentar vai muito mais além de ilustrar o texto. Os estudantes foram instigados a demonstrar entendimento se realmente incorporaram o conteúdo e se o utilizaram para entender a questão, já que se propôs a montagem para evidenciar o caminho do mercúrio até o corpo humano. Esse intento pressupõe a ampliação da percepção de não somente apropriar-se do saber, mas também torná-lo útil, aplicável a uma realidade.

Em relação a essa questão, Silva (2010, p. 42) reitera que:

[...] um trabalho que tenha a finalidade de formar um cidadão crítico, pressupõe evidenciar que a construção do conhecimento científico e tecnológico é calcada em intencionalidades, e que a sociedade intervém nesse processo [...].

É importante salientar que o conhecimento do conteúdo e das teorias relacionadas a este deve colaborar com a construção das inter-relações CTSA pelos próprios estudantes, visando entender o papel da Ciência. Pozo e Crespo (2009, p. 21) corroboram com esta assertiva ao afirmarem que "os discentes podem compreender as relações entre o desenvolvimento da ciência, a produção tecnológica e a organização social, entendendo, portanto, o compromisso da ciência com a sociedade".

Em relação às aulas práticas, uma delas ocorreu em paralelo com uma aula teórica. O processo de destilação foi escolhido por conta da temática desenvolvida, nesse caso a extração do ouro. No laboratório, foram propostas algumas situações em que os estudantes deveriam escolher e aplicar um dos métodos de separação de misturas dentre os apresentados.

Além dessa atividade, a turma foi dividida em seis grupos e cada um destes recebeu uma cópia do escrito de Sartori et al. (2009). Este foi apresentado e lido na sala 
de aula e discutiu-se a possibilidade de montagem de um destilador. Cada grupo ficou responsável por trazer os materiais necessários para a operacionalização da atividade.

$\mathrm{Na}$ preparação para a construção do aparelho, os grupos foram reunidos no laboratório de Ciências. Cada equipe seguiu os passos sob o acompanhamento e orientação do professor, até o momento da confecção. Com o destilador pronto, preparouse uma mistura de água, corante alimentício e álcool a fim de proceder ao processo de separação.

Nas anotações e nos relatos orais dos membros de cada equipe, a exposição das dificuldades, dúvidas, inquietações e até das expectativas foram de grande valia no processo de análise dos dados. Os estudantes se mostraram entusiasmados e envolvidos no decorrer da atividade. Ficou claro que o nível de compreensão do conteúdo tornou-se mais concreto, pois os educandos vivenciaram a relação teoria/prática dos conceitos científicos. Além disso, romperam com a visão de que as atividades científicas não estão atreladas somente aos cientistas e laboratórios com materiais sofisticados.

\section{Considerações finais}

Em uma sociedade em que os conhecimentos e produtos da Ciência e da Tecnologia estão presentes e são valorizados, o papel dos professores é o de colaborar para que os indivíduos e, especialmente, os discentes consigam compreender, inteirar-se e, mais ainda, participar ativamente das transformações oriundas do processo de desenvolvimento científico-tecnológico.

Ao propor a construção de uma sequência de aulas pautada nas inter-relações CTSA, na disciplina de Ciências, espera-se um novo direcionamento para o ensino e, juntamente com a prática diferenciada dos docentes, possa-se contribuir para aperfeiçoar as demandas educacionais na sociedade da informação e do conhecimento, em especial no tocante ao ensino de Ciências. Andrade e Vasconcelos (2014) corroboram com esse entendimento ao afirmarem que o docente tem o papel de estabelecer relações entre o conteúdo da disciplina com aspectos científicos e tecnológicos que envolvem a sociedade e interferem no ambiente, preparando os estudantes para a ação crítico-reflexiva perante as problemáticas socioambientais.

Sendo assim, ao rever as propostas curriculares para o Ensino Fundamental, reflete-se acerca do enfoque CTSA no ensino de Ciências, o que propicia um olhar mais específico com relação ao processo de ensino-aprendizagem nessa área.

Por certo, a iniciativa elaborada e desenvolvida por nós, aplicando os pressupostos discutidos ao longo do corpo do trabalho, foi apropriada, correspondendo às expectativas e necessidades dos sujeitos envolvidos. Ressalva-se que "cabe ao professor selecionar o melhor material disponível diante da sua realidade, e sua utilização deve ser feita de maneira que possa constituir um apoio efetivo e contínuo" (BIZZO, 2009, p. 86).

Sendo assim, colocar à disposição dos educadores propostas e experiências que os auxiliem em sua prática pedagógica e estejam de acordo com as expectavas atuais 
para o ensino contribuirá de forma positiva para a ruptura de um ensino desvinculado da realidade dos estudantes e mais ainda do conhecimento científico. É sabido que os currículos apresentam um número excessivo de conceitos, de definições, cuja interrelação é dificilmente percebida pelos alunos. Desse modo, tem-se uma ciência totalmente desvinculada da realidade, que requer mais memória do que 0 estabelecimento de relações. Em consequência, os conceitos passam a ser utilizados de forma mecânica na resolução de problemas e exercícios.

Por isso, apoiamos Oliveira (2009), que leva em consideração a complexidade da profissão docente, especificamente no caso do ensino de Ciências, dizendo que é fundamental compreender como esse profissional utiliza seus conhecimentos para planejar e executar sua prática docente, ainda mais em uma abordagem CTSA.

Neste sentido, acreditamos que a formação inicial e continuada de professores possam colaborar na preparação docente para a adequada inserção de uma pluralidade de estratégias de ensino na prática pedagógica, incluindo, principalmente, atividades práticas, além de teorias. Entretanto, mais que diversificar estratégias, é preciso trabalhar no sentido de explorá-las em toda sua potencialidade, proporcionando uma formação crítica que permita ao professor ter autonomia e iniciativa para superar entraves, procurando articular toda a equipe escolar. Deve-se ainda favorecer também 0 desenvolvimento do que propõe o enfoque CTSA e assim transformar e/ou alterar o processo de ensinar e aprender Ciências.

Corroboramos com Nardi (2009), quando assevera que a introdução de uma abordagem centrada no enfoque CTSA no ensino de Ciências demanda tempo para estudo e planejamento das múltiplas atividades a serem desenvolvidas durante a abordagem. Contudo, temos vários referenciais, além dos mencionados neste escopo, a exemplo dos PCN, bem como as orientações curriculares nacionais para que possamos contemplar em nossa prática aspectos relevantes ao aprendizado, não se esquecendo de ministrar o conteúdo, o que é importante. Ao mesmo tempo deve-se oferecer aos discentes condições para a discussão de temas de seu cotidiano que promovam interesse pela busca e construção do conhecimento, como observamos na prática desenvolvida.

Com esta análise, esperamos que as discussões acerca do ensino aqui expostas, bem como a compreensão de sua importância, mais especificamente na área de Ciências, por se tratar de um conhecimento universal, possam abrir caminhos para o seu enriquecimento didático-metodológico, tendo o enfoque CTSA como um parâmetro relevante a ser considerado nas aulas de Ciências.

Por fim, espera-se que as reflexões e discussões registradas neste escrito, a partir de exemplo prático envolvendo uma turma de alunos do Ensino Fundamental, possam se materializar em ações que levem à formação de indivíduos com uma identidade crítica e autônoma perante a sociedade. A educação, assim como o ensino de ciências, é produto de inter-relações complexas entre a sociedade, economia e política, de modo que o contexto pelo qual o país passa influencia decisivamente nos caminhos das políticas educacionais. 


\section{Referências}

ANDRADE, B. dos S; VASCONCELOS, C. A. de. O enfoque CTSA no ensino médio: um relato de experiência no ensino de biologia. Revista Scientia Plena, v. 10, n. 4, janeiro de 2014.

AULER, D. Alfabetização científico-tecnológica: um novo "paradigma"? Ensaio Pesquisa em Educação em Ciências, v. 5, n. 1, 2003.

BIZZO, N. Ciências: fácil ou difícil? São Paulo: Biruta, 2009.

BRASIL, Secretaria de Educação. Parâmetros curriculares nacionais: Ciências Naturais. Brasília: MEC, 1997.

KRASILCHIK, M. O Professor e o currículo das ciências. São Paulo EDUSP, 1997. (Coleção Temas Básicos de Educação e Ensino).

LOPES, A. Políticas curriculares: continuidade ou mudança de rumos? Revista Brasileira de Educação, n. 26, p.108-119, 2004.

LINSINGEN, I. V. Perspectiva educacional CTS: aspectos de um campo em consolidação na América Latina. Ciência e Ensino, v. 1, Número Especial. Novembro, 2007.

LUDKE, M. ANDRÉ, M. E. D. A. Pesquisa em educação: abordagens qualitativas. 11ª reimpressão. EPU: São Paulo, 1986.

MARCONDES, M. E. R; CARMO, M. P. do; Suart, R. C; et al. Materiais instrucionais numa perspectiva CTSA: uma análise de unidades didáticas produzidas por professores de química em formação continuada. Investigações em Ensino de Ciências, v. 14, n. 2, p. 281-298, 2009.

MORAES, J. U. P.; ARAÚJO, M. S. T. O ensino de física e o enfoque CTSA: caminhos para uma educação cidadã. São Paulo: Editora Livraria da Física, 2012.

NARDI, R (Org.) Ensino de ciências e matemática: temas sobre formação de professores. São Paulo: Acadêmica, 2009 (Coleção Ensino de Ciências).

OLIVEIRA, M. M (Org.) CTSA: experiências multi-interdisciplinares no ensino de ciências e matemática. Recife: Edições Bagaço, 2009 (Série Formação de professores, 2).

POZO, J. I; CRESPO, M. A. G. A aprendizagem e o ensino de ciências: do conhecimento cotidiano ao conhecimento científico. 5aㅗ ed. Porto Alegre: Artmed, 2009.

SANTOS, W. L. P. dos; SCHNETZLER, R. P. Educação em química: compromisso com a cidadania. 3ae ed., ljuí: Editora Unijuí, 2003.

SANTOS, M, E, V, M. Cidadania, conhecimento, ciência e educação CTS. Rumo a "novas" dimensões epistemológicas. Revista Iberoamericana de Ciencia tecnología y sociedad, v. 2, n. 6, Buenos Aires, 2005.

SANTOS, W. L. P. Contextualização no ensino de ciências por meio de temas CTS em uma perspectiva crítica. Ciência e Ensino, v. 1, número especial, novembro de 2008. 
SARTORI, E. R; BATISTA, E, F; SANTOS, V. B. dos; FATIBELLO-FILHO, O. Construção e aplicação de um destilador como alternativa simples e criativa para a compreensão dos fenômenos ocorridos nos processos de destilação. Revista Química Nova na Escola, v. 31, n. 1, Fevereiro de 2009.

SASSERON, L. H.; CARVALHO, A. M. P. Almejando a alfabetização científica no ensino fundamental: a proposição e a procura de indicadores do processo. Investigações em Ensino de Ciências, Porto Alegre, v. 13, n. 3, p. 333-352, 2008.

SILVA, K. M. A. Abordagem CTS no ensino médio: Um estudo de caso da prática pedagógica de professores de Biologia. Dissertação de mestrado. 2010. 161 f. (Mestrado em Educação em Ciências e Matemática) - Universidade Federal de Goiás, Goiânia, 2010.

TOMAZELLO, M. G. C. O movimento Ciência, Tecnologia, Sociedade - Ambiente na Educação em Ciências. Seminário Internacional de Ciência, Tecnologia e Ambiente, I, 2009, Paraná. Anais do I Seminário Internacional de Ciência, Tecnologia e Ambiente. Cascavel - Paraná: UNIOESTE, 2009.

Submissão: 09/06/2016 Aceite: $25 / 11 / 2017$ 